This item was submitted to Loughborough's Research Repository by the author.

Items in Figshare are protected by copyright, with all rights reserved, unless otherwise indicated.

\title{
Ethical issues in designing interventions for behavioural change
}

PLEASE CITE THE PUBLISHED VERSION

https://doi.org/10.21606/dma.2018.498

\section{PUBLISHER}

(c) The Authors. Published by the Design Research Society

\section{VERSION}

AM (Accepted Manuscript)

\section{PUBLISHER STATEMENT}

This work is made available according to the conditions of the Creative Commons Attribution-ShareAlike 4.0 International (CC BY-SA 4.0) licence. Full details of this licence are available at: http://creativecommons.org/licenses/by-sa/4.0/

\section{LICENCE}

CC BY-SA 4.0

\section{REPOSITORY RECORD}

Jun, Gyuchan Thomas, Fernando Carvalho, and Neil Sinclair. 2019. "Ethical Issues in Designing Interventions for Behavioural Change". figshare. https://hdl.handle.net/2134/32265. 


\title{
Ethical Issues in Designing Interventions for Behavioural Change
}

\author{
JUN Gyuchan Thomas ${ }^{\mathrm{a}^{*}}$; CARVALHO Fernando ${ }^{\mathrm{a}}$ and SINCLAIR Neil ${ }^{\mathrm{b}}$ \\ a Loughborough Design School, Loughborough University, UK \\ ${ }^{b}$ Department of Philosophy, University of Nottingham, UK \\ * Corresponding author e-mail: g.jun@lboro.ac.uk \\ doi: 10.21606/dma.2017.498
}

This paper reflects on fundamental ethical issues concerning designing for behavioural change, in order to raise questions about the factors that should be considered by design practitioners when developing interventions. It draws on existing literature on philosophical ethics, moral psychology and design. It proposes a list of ethical questions and considerations to be made throughout the design process. A case study addressing behavioural changes in antibiotics prescriptions (for Urinary Tract Infections) was carried out to demonstrate how the ethical questions identified are asked and considered. We provide a framework for addressing these issues with the hope that it will help minimise the risk of problematic and unethical intervention design processes.

behavioural change, ethics, healthcare, design participation

\section{Introduction}

Behavioural insights have been successfully applied to narrow the gap between 'desirable' and 'undesirable' behaviour in various health and public services (The Cabinet Office Behavioural Insights Team, 2010; Perry, Chhatralia, Damesick, Hobden \& Volpe, 2015; Hallsworth et al., 2016). The field of design has been shown to make substantial contributions to this area, as it offers a variety of methods and tools that can facilitate the creation of effective interventions which can narrow the gap (often in unexpected, nudging, ways). However, the process of designing for behavioural change can be unethical or counterproductive if a set of important issues - pertaining both to the practical and the philosophical realms - are not carefully considered.

The primary questions that arise as a result of considering the potential ethical dimensions of designing for behavioural change are:

1. Why do people persist with 'undesirable' behaviour? (Questions of moral psychology) 
2. What is 'desirable' behaviour? (Questions of philosophical ethics)

3. How can the gap between 'undesirable' and 'desirable' behaviour be narrowed in an ethically acceptable way? (Questions of design ethics)

Figure 1 maps the primary questions into the main components of designing for behavioural change: undesirable behaviour; intervention; desirable behaviour.

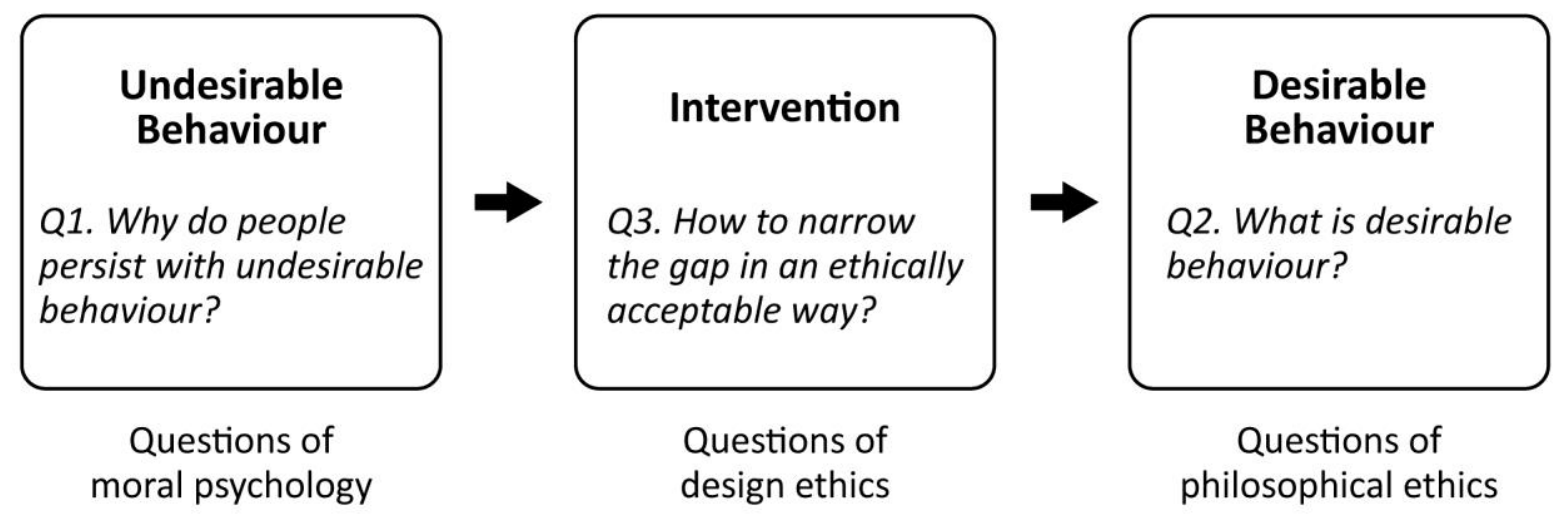

Figure 1: Primary ethical questions in designing for behavioural changes

The purpose of this paper is to explore these questions and the considerations relevant to answering them, based on existing literature on philosophical ethics, moral psychology and design. We aim to develop a provisional framework for ethical considerations in designing interventions for behavioural change. A case study addressing antibiotics prescription (for Urinary Tract Infections) is described, to demonstrate how the ethical questions are asked and considered.

\section{Approach}

This paper consists of two parts: analysis of existing literature and a case study. The literature analysis involved the purposeful identification and choice of the literature relevant to the primary questions addressed in the paper. The process was supported and informed by the authors' expertise in philosophical ethics, human factors and design for behaviour change. This first study informed the development of a provisional ethical framework for designing for behavioural change.

The subsequent case study aimed to demonstrate how the framework would work in an ongoing behaviour change field study in a clinical setting. In this way, we explore the overarching ethical concerns influencing behavioural change intervention design.

The rest of the paper is structured as follows. In section 3.1, we consider the issue of why people persist with undesirable behaviour and discuss a key role played by environmental, social and historical factors. In section 3.2, we draw on existing work in both design studies and moral philosophy distinguishing four key questions that must be examined in any particular attempt to address the issue of identifying desirable behaviour. In section 3.3, we consider ethical ways of narrowing this gap, and identify two key requirements which ethical interventions must meet. In section 4, we apply the theoretical considerations developed in section 3 to a case study. The case study looked at the ethical implications of the processes of designing interventions for antibiotic prescription behaviour change for Urinary Tract Infection (UTI) treatment in older adults within the Emergency Department (ED) of a hospital in England.

\section{Literature Analysis}

\subsection{Why people persist with undesirable behaviour?}

There are many models that help shed light on the determinants and mechanisms of human behaviour. Most comprehensive models recognise that behaviour is the result of an interplay of 
factors, some of which are individual-based in nature, some of which relate to social norms or environmental variables. Such models improve on a traditional 'individualistic model' (sometimes called the 'medical model') according to which 'bad' behaviour is simply the consequence of bad choice. In line with Ecological Theory, they incorporate environmental, historical and social factors external to the individual - as partial influencers of the personal behaviour (Guttmacher, Kelly \& Ruiz-Janecko, 2010; Niedderer et al., 2016). The importance of such contextual variables, especially in clinical settings such as the one providing the case study here, is reinforced by Dixon (2016). Dixon notes that changes in clinical practice can take any number of years: from a discouraging average of seventeen years up to the unfathomable span of a couple of centuries - as is shown in the case of translating the knowledge that handwashing reduces infections to routine practice. Empirical research in moral psychology also supports these findings: according to Doris (2002) traditional moral theory has systematically overplayed the influence of stable character in determining behaviour, to the detriment of environmental or 'situational' factors. As Doris puts it: "behaviour is extraordinarily sensitive to variation in circumstance ... The experimental record suggests that situational factors are often better predictors of behaviour than personal factors" (2002, p.2).

One model which considers both individual and situational factors is the COM-B model introduced by Michie, van Straten \& West (2011). The model describes human behaviour as being the product of the dynamics between capability (psychological and physical characteristics of individuals), opportunity (social norms and environmental factors that influence and circumscribe people in society), and motivation (emotional responses and reflective plans that drive action). Following this rationale, we can presume that the reasons for persisting with undesirable behaviour may be due to a number of determinants, pertaining to one or more of the three components of the model. As also suggested by the aforementioned authors, it is only through analysis of the specific context and the people in question that we can reach reliable conclusions about why people consistently 'misbehave'.

Hale and Borys' approach (2013) as to why people violate safety rules (i.e. desirable behaviour) can also provide a complementary account of the reasons why some (mis)behaviours are persistent. Four factors found to be relevant to violation were: (1) individual characteristics, e.g. personality; (2) organisational factors, e.g. lack of monitoring, culture, leadership; (3) hardware factors, e.g. poor ergonomic design; (4) rule-related factors, e.g. poorly designed, out-dated, and conflicting rules.

Summarising, the two fundamental messages to bear in mind here are that not all bad behaviour is the result of bad choice or poor individual capacities and that, if behaviours can be understood and explained, they can also be intentionally influenced and changed.

However, existing ethical discussion concerning behavioural change interventions does not always take these comprehensive perspectives into account, partly because the traditional individualist model gives diminished importance to environmental factors and social context in determining or constraining individual and collective behaviours. Welsh (2016) concurs: he is emphatic in his criticism that most behavioural change approaches assign too much responsibility to agency and self-efficacy without much consideration to variables of a social or contextual nature. He supports his contention by evidencing the inability of these approaches to distinguish the extent to which the specific behaviour of individuals is pre-encapsulated within a broader spectrum of acceptable, appropriate behaviours that are historically determined and socially embedded. His illustration makes use of a previously identified distinction between 'practice as performance' and 'practice as entity' (as in Spurling, McMeekin, Shove, Southerton \& Welsh, 2013) to criticise what he calls the 'portfolio model' of behavioural change, "wherein the subject is presumed to possess a more or less stable portfolio of values, attitudes, norms, interests and desires, and selects from them to decide on the course of action" (Welsh, 2016), regardless of context. Welsh's resolution advocates, in turn, a deeper focus on the systemic, sociotechnical, and organisational factors that act as preconditions for individual behaviour. Following this perspective, one could raise questions about whether certain contexts, instead of individuals, are more favourable to ethical practices than others. 
Therefore, to establish, with a reliable degree of certainty, the reasons why people persist with 'undesirable' behaviour, even when it causes prejudice to themselves (for example with unhealthy habits like smoking) is a task that demands caution and attention to factors that go beyond personal characteristics, and thus can point to determinants beyond the reach of individual agency (such as environmental, historical and social factors).

\subsection{What is 'desirable' behaviour?}

Defining whether a particular type of behaviour is 'desirable' immediately raises more questions. Assuming that a type of 'behaviour' is desirable (or not) primarily on the basis of its effects on people, we need to ask:

(i) Who is affected by the type of behaviour?

(ii) What are the interests of those affected?

(iii) What are the conflicts between those interests?

(iv) (In light of those conflicts:) What is collectively desirable?

Desirability in designing for behavioural change is usually indexed to a group (e.g. 'users'), but behaviour that is desirable for a group of individuals may be so only under certain conditions and may not be desirable to another group. For example, it may be desirable for a single individual to graze their cattle on common land (or access a database at a particular time), but if everyone does the same, the common land will be eroded (or the database will crash), resulting in undesirable outcomes for all. This is the well-known tragedy of the commons (Hardin 1968). In other cases, what is desirable for one individual may be undesirable for another, again resulting in situations where what is desirable for individuals cannot be simply aggregated into a single desirable outcome for the group.

Tromp, Hekkert \& Verbeek (2011) suggest that the principal reason for the existence of a gap between 'undesirable' and 'desirable' behaviour may rest on a mismatch between the concerns of the individual and those of the group - "the individual does not always embrace or prioritize collective concerns." Tensions between individual and collective perspectives on priorities, and on the desirability or pertinence of certain behaviours over other competing alternatives, certainly pose a major challenge.

What these approaches suggest is the need to distinguish clearly between issues of desirability for individuals, and issues of desirability for groups or collectives. It is here that philosophical ethics can help, for philosophers have developed theories of both types of value, as well as views on the connections between them.

Begin, then, with desirability for individuals. J.S. Mill famously argued that 'the sole evidence it is possible to produce that anything is desirable, is that people do actually desire it' (1861, ch. IV). But this cannot be correct since it is commonplace that individuals desire things which they themselves do not consider desirable for them (e.g. smokers who are struggling to quit). A natural response to this problem (exemplified in Halpern et al.'s focus on well-informed choices, see below $\S 3.3$ ) is to idealise: what determines desirability for an individual is not what they actually desire, but what they would desire under some idealised conditions (the locus classicus of such 'ideal observer' theories is Firth, 1952). In this vein, Railton (1986) has argued that something is desirable for an individual just in case an idealised counterpart of that individual would want her non-idealised self to desire that thing. So, for example, an inoculation injection is desirable for an individual just in case an idealised version of that individual would want her non-idealised self to want the injection. According to Railton, the idealised individual is idealised insofar as she possesses "unqualified cognitive and imaginative powers" and "full factual and nomological information" about the desirable object. In this case, she knows about the possible effects and side-effects of the injection, 
the rationale linking injections to susceptibility of disease, she can vividly imagine both the pain caused by the injection and the effects of contracting the disease it inoculates against, and so on.

This gives an account of desirability for individuals, but can also be the basis of an account of desirability for groups. The guiding thought is that whereas desirability for individuals is the result of idealising an individual perspective, desirability for groups is the result of idealising - or constructing - a collective perspective. One way of doing this is to imagine an idealised individual who, in circumstances of full and vivid information, and again with full cognitive and imaginative powers, considers equally the interests (that is, individually desirable objects) of all potentially affected individuals. What would be rationally approved of by such an individual is what is desirable for the group (Railton, 1986, p.198). In particular, this individual is fully informed insofar as she is aware of the potential consequences of group action (such as the negative effects of everyone performing some action in tragedy-of-the-commons situations) and of the potential conflicts between what is desirable for distinct individuals.

The upshot is as follows. Where design interventions concern the potentially conflicting behaviour of a group of individuals, we define what is desirable behaviour in terms of what would be approved by an ideally informed rational individual considering equally the interests of all potentially affected individuals. In turn, the interests (desirable things) for those individuals are defined in terms of what idealised - fully-informed - counterparts of those individuals would want them to want. So, there are two steps of idealisation: one individual and one collective.

What this means in practice is that design practitioners should consider a series of the following questions prior to intervention design:

(i) Who is affected by the type of behaviour?

(ii) What are the interests of those affected?

(iii) What are the conflicts between those interests?

(iv) (In light of those conflicts:) What is collectively desirable?

In answering these questions, scientific and empirical investigations (concerning the causes and effects of particular behaviours, collective patterns of behaviour, their cost and benefits and so on) will be relevant but not decisive. The two stages of idealisation (individual and collective) require full awareness of relevant empirical facts, but also require a deal of empathy and moral judgement in balancing competing considerations. The framework we propose does not provide simple algorithms for answering these non-scientific questions (and indeed there would be something unnervingly robotic if there were such algorithms - see Hursthouse, 1998). Rather its aim is more modest: to provide better solutions by providing a clearer framework of questions to ask.

Desirable behaviour is often highly contextual, since what would be desired and approved of in idealised conditions must be sensitive to the particular features of the situation being judged. Defining desirable behaviour will also involve canvassing the views of those potentially involved (as is common, for example, in the subjective, survey-based discipline 'happiness studies'), but will not simply defer to present concerns - rather it will defer to concerns as revealed by idealisation. In this regard, Halpern et al. (below §3.3) are correct to focus on well-informed choices. Simultaneously, our approach suggests an inclusive perspective concerned with engaging perspectives of all potentially involved groups.

Hence, according to our approach, a strategy for advancing knowledge of 'desirable behaviour' requires trustworthy evidence that can provide the hard data to elucidate facts, an informed understanding on the nature of the problems in question, and qualities of empathy, imagination and judgement to discern and balance competing concerns. A potential strategy to achieve that will be further discussed in the next section. 


\subsection{How to narrow the gap?}

There are many occasions when the only way to narrow the gap between 'undesirable' and 'desirable' behaviour is to devise an intervention to intentionally change behaviour. Interventions can be effective because they help people achieve more desirable behaviours by properly acting on the specific determinants of bad behaviour, whether they concern individual components (skills, beliefs, habits etc.) or external factors (rules, time constraints, lack of resources, social or cultural norms) that obstruct or prevent the performance of the desirable behaviour.

The Design for Socially Responsible Behaviour approach (Tromp et al., 2011) fosters a practice within which one of the central efforts is to align the behavioural objectives of persons and the larger group through design processes. This approach provides a number of tactics which aim at 'bridging the concerns' of individuals and community so as to facilitate the desirable behavioural outcome. Depending on the intended level of influence, designers may choose approaches that range from persuasive (reason-based) to coercive (threatening), and from seductive (providing pro tanto reasons) to decisive (providing conclusive reasons). However, although promising this approach does not specify a method for determining individual group interests and seems to conflate psychological concerns with desirability - a mismatch between the actual concerns of the individual and the group need not entail a mismatch between what is desirable for each, since our actual concerns do not always map onto what is truly desirable (see above, in connection with J.S. Mill).

Another possible strategy to address the conflict between individuals and groups is suggested by Halpern and colleagues (2004) in their perspective of a shared responsibility between people, community, and the state. Halpern et al. propose a set of conceptual tools that can aid in case-bycase decisions regarding the definition of what is 'desirable behaviour', in conjunction with who is to act upon it. They present a view in which individuals have responsibilities over their well-informed choices, whereas governments should account for the factors that extrapolate individual possibility; both of which can be assessed when the causes of behaviour are at stake. Alongside, sometimes in spite of unclarity on the causes and responsibilities of a behaviour, assigning ultimate responsibility can be further considered on the basis of the possible impacts on third parties (people that cannot account for their own decisions, children, animals) or the environment (nature, public spaces, the workplace). All of these occur under the overarching perspective that there are a priori, value-based judgements on the rights and responsibilities of individuals that are empirically reinforced or challenged by the values of society at large (Halpern et al., 2004).

Interventions can be put to action by the means of varied Behaviour Change Frameworks, which suggest stepwise stages to enable the systematic development, piloting, implementation and evaluation of a set of activities. Such frameworks aim to eliminate barriers and provide the means necessary to narrow the gap between 'undesirable' and 'desirable' behaviour. The reviews by Darnton (2008) and Niedderer et al. (2016) have identified numerous approaches developed for a range of purposes.

Interventions, in order to be ethical, would need to combine two core aspects. First, they must be based on trustworthy evidence that feeds into well-informed opinions, meaning that the determination of the ultimate ends to which the intervention is aiming would have to be based on the best available evidence to describe the relevant facts in question. Second, they must enable the views and voices of the multiple stakeholders involved in, and impacted by, the intervention to be properly represented and embedded in the processes of change. Most frameworks do a good job in accounting for evidence. However, in our view, they do not provide the means to address stakeholder participation to the proper extent, so as to assure that not only outcomes are effective, but the processes to achieve the results are not ethically objectionable.

A review by Lilley and Wilson (2013) focuses on the ethical dimensions of existing approaches to the field of designing for sustainable behaviour and reveals that "there is little or no integration of 
ethical considerations into these design process models and the provision of suitable tools to aid in prompting ethical reflection is lacking".

Lilley and Wilson's contribution substantially adds to the intervention process by the means of two mechanisms. First, they call attention to the fact that most existing approaches will only include stakeholder input later in the design process, when the purpose of the intervention has already been mostly defined (i.e. when desirability has been already established). Secondly, they explicitly include 'ethical reviews' that should be sought at three key moments of the intervention design process when identifying the behaviour, when formulating the intent, and when evaluating the outcomes.

Lilley and Wilson focus on the work process of designers, putting the morality of decisions in their hands, which is reasonable if the resulting outcome is the development of products, because such activity depends on technical expertise which could be seen as exclusive to professionals. There are well-defined standards of desirability integral to each product (e.g. the aim of a coffee machine is to make damn fine coffee). There might be, however, a tendency to wrongfully position products (and design) in relative isolation from social context while the importance of user input might be recognised throughout the intervention process.

In order to encompass ethical approach to behaviour change, it is important to make sure a broad range of stakeholder participation is considered and engaged whenever decisions need to be made, regarding both the dynamics of the process in itself (how to do things) and the intended outcomes envisioned as desirable (what things to do). Particularly when design interventions focus on external environmental factors as the determinants of action, the mechanism of that change may not be processed through the conscious deliberation or reasoning of the affected agents. In such cases designers need to make sure that participants, who are information providers, are also provided with well-balanced suitable information for rational and considered thinking so that they would consent to having their actions influenced in such ways (the requirement for such consent being one of the key insights of Kantian ethics, with its focus on respecting individual autonomy - see Kant, 1785). In sum, in order to be fully ethical, intervention design processes need to be truly participatory.

There are different levels of participation. User input, which is central in user-centred design, can be interpreted as mere consultation. There could be two different levels of participation from having a voice (having an opinion about something) and having a say (affecting the outcome of an activity with what you say) (Bratteteig, Bodker, Dittrich, Mogensen \& Simonsen, 2013). Hence, full participation is hardly achieved by means of consultation only.

Designing for behaviour change is not necessarily to devise objects (products) or even services, but to discuss the very processes that enable the development of change, in which case the distinction between experts and lay people no longer holds much distinctive value. Robertson and Simonsen (2012) claimed that:

\section{[...] the question of how participation is being negotiated and defined (and by whom) is fundamental to distinguishing Participatory Design from the more common user-centred approaches. Participatory Design projects are always driven by ongoing and systematic reflection on how to involve users as full partners in design and how this involvement can unfold throughout the design process.}

Balka (2010) goes even further to say that it is within the democratisation processes of people being able to influence change in organisational structures that authentic participatory results will be found. And, that a dual emphasis on process and outcomes is necessary to give rise to true participation; by themselves, neither 'feel good processes' that do not deliver good results, nor 'good outcomes' that did not come from an engagement process are sufficient to constitute real, and, hence, ethical participation. However, participatory design, which might be essential to 
designing behavioural change interventions in an ethically acceptable way, has many practical challenges to overcome.

To demonstrate how the proposed framework and questions (Figure 2) can be utilised, the case of a behavioural change project concerning antibiotics over-prescription behaviour is presented in the next section.

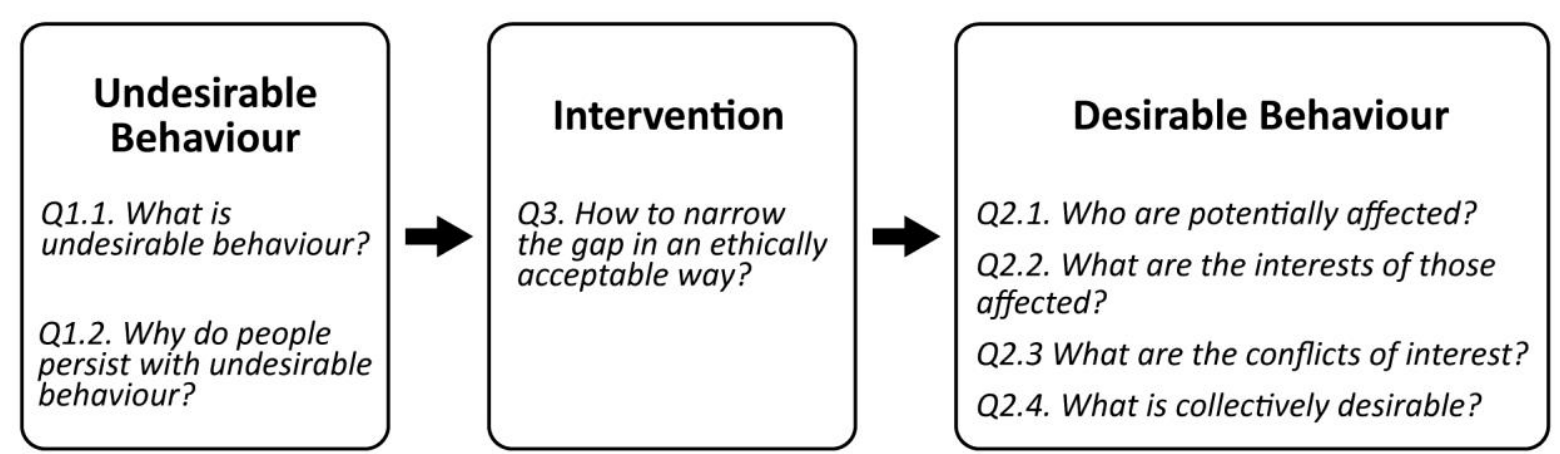

Figure 2 Framework proposed for exploring ethical questions in designing interventions for behavioural change

\section{Case Study}

The National Institute for Clinical Excellence (NICE) in England recommends prescribing antibiotics for adults over 65 years only in the presence of pathogens in the urine and clinical signs and symptoms (groin pain, confusion, difficulty passing urine etc.). However, evidence has indicated that staff often inappropriately diagnose Urinary Tract Infections (UTI) in older adults because they are more likely to have bacteria in urine, without any clinical symptoms of infection (Woodford, 2009). Recent qualitative research on hospital physicians has observed that prescribing of antibiotics for patients without symptoms of UTI (asymptomatic bacteriuria) is driven by overreliance on laboratory test results, difficulties in interpreting symptoms, anxiety about complications and peer culture (Eyer, 2016).

Antimicrobial resistance is a global public health concern caused mainly by "the systematic misuse and overuse of drugs in human medicine and food production" (WHO, 2015) and it has been observed in all regions of the world. In medicine, the causes for the persistent adoption of nonoptimal practices regarding the prescription of antibiotics is manifold and it has been identified in the management and treatment of various conditions and illnesses, as well as in different contexts, ranging from the GP office to the Emergency Department of hospitals worldwide. There is urgent need to design interventions to change staff behaviour on infection management and antibiotic prescription, but various ethical issues and questions need to be carefully considered prior to or during the intervention design process. Table 1 is created to demonstrate how the framework, aforementioned in this paper, can be applied for clinical staff behaviour change on Urinary Tract Infection management and treatment.

Table 1 Application of the framework for understanding ethical questions and the main issues at stake concerning Urinary Tract Infection (UTI) diagnosis and management at the Emergency Department

\begin{tabular}{lll}
\hline Stages & $\begin{array}{l}\text { Questions to be } \\
\text { asked }\end{array}$ & Example from case study \\
\hline $\begin{array}{l}\text { Undesirable } \\
\text { behaviour }\end{array}$ & $\begin{array}{l}\text { What is undesirable } \\
\text { behaviour? }\end{array}$ & $\begin{array}{l}\text { - Inappropriate diagnosis of UTI } \\
\text { - Over-prescription of antibiotics for UTI }\end{array}$ \\
\cline { 2 - 3 } & $\begin{array}{l}\text { Why do people persist } \\
\text { with undesirable } \\
\text { behaviour? }\end{array}$ & $\begin{array}{l}\text { - Individual factors: knowledge, skills, beliefs, motivations, } \\
\text { experience and self-efficacy }\end{array}$ \\
& - Environment factors: maximum four-hour wait target at
\end{tabular}


emergency department, conflict with a sepsis protocol, wider organisational culture and NHS pressure

\begin{tabular}{|c|c|c|}
\hline \multirow[t]{4}{*}{$\begin{array}{l}\text { Desirable } \\
\text { behaviour }\end{array}$} & $\begin{array}{l}\text { Who are potentially } \\
\text { affected? }\end{array}$ & - Staff, patients, carers, tax payers and public \\
\hline & $\begin{array}{l}\text { What are interests of } \\
\text { those affected? }\end{array}$ & $\begin{array}{l}\text { - Staff: treat patient within 4-hour target } \\
\text { - Patients: get well soon } \\
\text { - Tax payers: effective use of health budget } \\
\text { - Public: antimicrobial stewardship (appropriate use of } \\
\text { antibiotics) }\end{array}$ \\
\hline & $\begin{array}{l}\text { What are conflicts of } \\
\text { interests? }\end{array}$ & $\begin{array}{l}\text { - Conflict between efficiency (4hr A\&E target) and public } \\
\text { health (antimicrobial stewardship) } \\
\text { - Conflict between short-term goal ( } 4 \mathrm{hr} \text { A\&E target) and long- } \\
\text { term goal (antimicrobial stewardship) } \\
\text { - Conflict between sepsis management (quick antibiotic } \\
\text { prescription) and UTI management (careful antibiotic } \\
\text { prescription) } \\
\text { - There are multiple conflicts regarding both one single } \\
\text { stakeholder, and between multiple stakeholders }\end{array}$ \\
\hline & $\begin{array}{l}\text { What is collectively } \\
\text { desirable? }\end{array}$ & $\begin{array}{l}\text { - Need to take into account all the conflicts at multiple levels } \\
\text { and dimensions } \\
\text { - Need both hard data to elucidate facts, an informed } \\
\text { understanding on the nature of the problems in question, } \\
\text { and qualities of empathy, imagination and judgement to } \\
\text { discern and balance competing concerns }\end{array}$ \\
\hline Intervention & $\begin{array}{l}\text { How to narrow the gap } \\
\text { in an ethically } \\
\text { acceptable way? }\end{array}$ & $\begin{array}{l}\text { - Trustworthy evidence: new guideline adopted by the } \\
\text { National Institute for Clinical Excellence in England } \\
\text { - Well-informed opinions: competing concerns including the } \\
\text { possible impacts on third parties (people that cannot } \\
\text { account for their own decisions, children, animals) or the } \\
\text { environment (nature, public spaces, the workplace) } \\
\text { - Participatory design: engage staff, patients, carers, tax } \\
\text { payers, and public }\end{array}$ \\
\hline
\end{tabular}

Defining an ethical approach to address UTI diagnosis and management in the Emergency Department requires a holistic understanding of the multiple factors at play. The first stage is to define what is undesirable behaviour. This case has two behaviours: inappropriate diagnosis of UTI, and inappropriate antibiotic prescription. Complex interplay between individual and environment factors are found concerning why staff persist with the undesirable behaviours. The second stage is to ask questions around stakeholders, their interest and conflicts. Multiple stakeholders for this case include staff, patients, carers, tax payers, and the general public. It helps to clarify diverse interests and identify conflicts at multiple level and dimensions (within one single stakeholder, and between multiple stakeholders; short-term and long-term; productivity and safety etc). the question on conflicts really helps to clarify complex dynamics, but it is still very challenging to decide what is collectively desirable. The third intervention design stage require participatory design approach based on trustworthy evidence and well-informed stakeholders. Behaviour change interventions can then be developed to tackle the multiple determinants of undesirable behaviours by applying the best available evidence and theory and by means of participatory processes. Active participation of the stakeholders can be enabled throughout the entire intervention cycle. This approach would account for effective outcomes and ethical ways of intervention design and implementation. Moreover, this approach is generalisable beyond this particular case: wherever design practitioners 
face circumstances characterised by an existing gap between desirable and undesirable behaviour, the questions and methods outlined in this paper can help those practitioners both identify more clearly what the desirable behaviour is, and identify means to bridge that gap in effective and ethically appropriate ways.

\section{Conclusion: How can Design for Behavioural Change Be Ethical?}

The purpose of the study was to reflect on fundamental ethical issues concerning designing for behavioural change, in order to raise questions about the factors that should be considered by design practitioners when developing interventions for change. This research has identified three potential ethical dimensions (moral psychology, philosophical ethics and design ethics) and provided a framework consisting of seven questions across three dimensions. The case study demonstrated the utility of the framework in systematically considering ethical issues around designing interventions for clinical staff's UTI diagnosis and antibiotic prescription behaviour. How to practically address complex ethical issues identified from the framework remains to be further explored in additional cases on a variety of design interventions.

\section{Acknowledgements}

This study is part of an ongoing reflection stemming from a collaborative effort to implement a behaviour change intervention aiming at improving UTI management and treatment within the Emergency Department of the Leicester Royal Infirmary/University of Leicester. We would like to acknowledge that some of the insights leading to the ideas presented in this paper build from the authors' interactions with a group of healthcare professionals participating in our study, as well as from a previous qualitative study carried out by, to whom we are grateful.

This paper was carried out as the results of the collaboration supported by the Philosophy Ergonomics and Application for Complex Human Systems (PEACHS) conference 2016.

Mr Fernando Carvalho is a scholarship recipient of the Science without Borders Programme, funded by CNPq/Ministry of Science, Technology and Innovation of Brazil.

\section{References}

Balka, E. (2010). Broadening discussion about participatory design: A reply to Kyng. Scandinavian Journal of Information Systems, 22: Issue 1, Article 7.

Bratteteig, T., Bodker, K., Dittrich, Y., Mogensen, P. H. \& Simonsen J. (2013). Methods: Organising principles and general guidelines for Participatory Design projects. In J. Simonsen \&T. Robertson (Eds.), Routledge International Handbook of Participatory Design (Chap. 6, pp. 117-144). New York: Routledge.

The Cabinet Office Behavioural Insights Team (2010). Applying Behavioural Insight to Health. London: The Cabinet Office Behavioural Insights Team.

Cadogan, S., McHugh, S., Bradley, C., Browne, J., \& Cahill, M. (2016). General practitioner views on the determinants of test ordering: a theory-based qualitative approach to the development of an intervention to improve immunoglobulin requests in primary care. Implementation Science, 11(1).

Charani, E., Castro-Sanchez, E., Sevdalis, N., Kyratsis, Y., Drumright, L., Shah, N. \& Holmes, A. (2013). Understanding the determinants of antimicrobial prescribing within hospitals: The role of "prescribing etiquette". Clinical Infectious Diseases, 57(2), 188-196.

Cullinan, S., Fleming, A., O’Mahony, D., Ryan, C., O’Sullivan, D., Gallagher, P. \& Byrne, S. (2014). Doctors' perspectives on the barriers to appropriate prescribing in older hospitalized patients: A qualitative study. British Journal of Clinical Pharmacology, 79(5), 860-869.

Darnton, A. (2008). Reference Report: An Overview of Behaviour Change Models and Their Uses (GSR Behaviour Change Knowledge Review). London: Government Social Research Unit.

Dixon, J. (2016). Spreading improvement: how to accelerate and the importance of archetypes. In: Health Lab, The Future of People-Powered Health: Insights from Leaders and Thinkers on How Digital and Social Innovation Can Contribute to Better Outcomes. London: Nesta.

Doris, J. (2000). Lack of Character: Personality and Moral Behavior. Cambridge: Cambridge University Press.

Eyer, M. M., Läng, M., Aujesky, D. \& Marschall, J. (2016). Overtreatment of asymptomatic bacteriuria: a qualitative study. Journal of Hospital Infection, 93(3), 297-303. 
Firth, R. (1952). Ethical absolutism and the ideal observer. Philosophy and Phenomenological Research, 12: 317-345.

Guttmacher, S., Kelly, P. J. \& Ruiz-Janecko, Y. (2010). Community-Based Health Interventions: Principles and Applications. San Francisco: Jossey-Bass.

Hale, A. \& Borys, D. (2013). Working to rule, or working safely? Part 1: A state of the art review. Safety Science, 57, 207-221.

Halpern, D., Bates, C., Mulgan, G., Aldridge, S., Beales, G. \& Heathfield, A. (2004). Personal Responsibility and Changing Behaviour: The State of Knowledge and Its Implications for Public Policy. London: Prime Minister's Strategy Unit.

Hallsworth, M., Snijders, V., Burd, H., Prestt, J., Judah, G., Huf, S. \& Halpern, D. (2016). Applying Behavioural Insights: Simple Ways to Improve Health Outcomes. Doha, Qatar: World Innovation Summit for Health.

Hardin, G. (1986). The Tragedy of the Commons. Science, 162: 1243-1248.

Hursthouse, R. (1998). Normative Virtue Ethics. In Roger Crisp (ed.), How Should One Live? Essays on the Virtues. Oxford: Clarendon Press.

Kant, I. (1785). Groundwork of the Metaphysics of Morals. In M.J. Gregor (ed.) (1998), Cambridge Texts in the History of Philosophy. Cambridge: Cambridge University Press.

Lilley, D. \& Wilson, G. (2013). Integrating ethics into design for sustainable behaviour. Journal of Design Research, 11, 278-299.

Michie, S., van Straten, M. \& West, R. (2011). The behaviour change wheel: A new method for characterising and designing behaviour change interventions. Implementation Science, 6:42.

Michie, S., Atkins, L. \& West, R. (2014). The Behaviour Change Wheel: A Guide to Designing Interventions. London: Silverback Publishing.

Mill, J.S. (1861). Utilitarianism, In G. Sher (ed.) (1979), Indianapolis: Hackett Publishing Company.

Niedderer, K, Ludden, G., Clune, S. J., Lockton, D., Mackrill, J., Morris, A., Cain, R., Gardiner, E., Evans, M., Gutteridge, R. \& Hekkert, P. (2016). Design for behaviour change as a driver for sustainable innovation: Challenges and opportunities for implementation in the private and public sectors. International Journal of Design, 10(2), 67-85.

Nuffield Council on Bioethics (2007). Public Health: Ethical Issues. Cambridge: Cambridge Publishers Ltd.

O'Kelly, K., Phelps, K., Regen, E., Kondova, D., \& Conroy, S. (2016). A qualitative study investigating the behavioural and psychological factors contributing to the misdiagnosis of urinary tract infection in adults "to dip or not to dip". [poster] In: EUGMS Congress, Lisbon: EUGMS.

Perry, C. Chhatralia, K., Damesick, D. Hobden, S. \& Volpe, L. (2015). Behavioural Insights in Healthcare: Nudging to Reduce Inefficiency and Waste. London: The Health Foundation.

Railton, P. (1986). Moral Realism, Philosophical Review 95. 163-207.

Robertson, T. \& Simonsen, J. (2012) Challenges and opportunities in contemporary Participatory Design. Design Issues, 28, 3-9.

Spurling, N., McMeekin, A., Shove, E., Southerton, D. \& Welsh, D. (2013). Interventions in Practice: Re-Framing Policy Approaches to Consumer Behaviour (SPRG Report). (www.sprg.ac.uk).

Tokin-Crine, S., Yardley, L., Coenen, S., Fernandez-Vandellos, R., Krawczyk, J., Touboul,P., Verheij, T. \& Little, P. (2011). GPs' views in five European countries of interventions to promote prudent antibiotic use. British Journal of General Practice, 61, e252-e261.

Tromp, N., Hekkert, P. \& Verbeek, P. (2011). Design for socially responsible behavior: A classification of influence based on intended user experience. Design Issues, 27, 3-19.

Welsh, D. (2016). Social practices and behaviour change. In F. Spotswood (Ed.), Beyond Behaviour Change: Key Issues, Interdisciplinary Approaches and Future Directions (Chap. 12, pp. 237-255). Bristol: Policy Press.

Woodford, H. J. \& George, J. (2009). Diagnosis and management of urinary tract infection in hospitalized older people. Journal of the American Geriatric Society, 57:107-114.

World Health Organization (2015). Global Action Plan on Antimicrobial Resistance. Geneva: WHO.

\section{About the Authors:}

Gyuchan Thomas Jun, PhD, is Senior Lecturer in Human Factors and Complex Systems at Loughborough University. His research has been on applying humancentred system design approaches to healthcare, transportation and energy systems. He is a producer of highly praised system safety animation series www.systemsafetylab.com 
Fernando Carvalho, MFA, is a designer currently pursuing a PhD degree at Loughborough Design School. Fernando's research looks at how to integrate behaviour change and participatory design to facilitate changes in healthcare staff practice within the National Health Service of England.

Neil Sinclair, PhD, is Associate Professor of Ethics at the University of Nottingham and winner of the 2016 Sanders Prize in Metaethics. His most recent publication is a collection on The Naturalistic Fallacy (forthcoming with Cambridge University Press). Full bibliography here: https://philpapers.org/profile/10227 